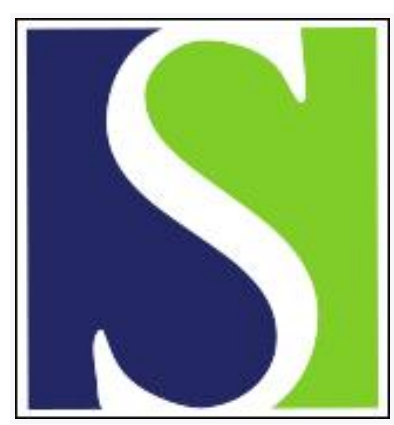

Scand J Work Environ Health 1989;15(2):111-116

https://doi.org/10.5271/sjweh.1874

Issue date: Apr 1989

Noise exposure during pregnancy and selected structural malformations in infants.

by Kurppa K, Rantala K, Nurminen T, Holmberg PC, Starck J

Affiliation: Institute of Occupational Health, Helsinki, Finland.

This article in PubMed: www.ncbi.nlm.nih.gov/pubmed/2772573

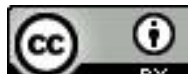




\title{
Noise exposure during pregnancy and selected structural malformations in infants
}

\author{
by Kari Kurppa, MD, Kaarina Rantala, MSc(ChemEng), Tuula Nurminen, MSc, \\ Peter C Holmberg, MD, Jukka Starck, PhD ${ }^{1}$
}

\begin{abstract}
KURPPA K, RANTALA K, NURMINEN T, HOLMBERG PC, STARCK J. Noise exposure during pregnancy and selected structural malformations in infants. Scand J Work Environ Health 1989;15:111-6. The study tested the hypothesis of exposure to noise during pregnancy being teratogenic. It included 1475 Finnish mothers who had given birth to a malformed child (orofacial cleft or structural defect of the central nervous system, skeleton, or heart and great vessels) and 1475 reference mothers. A special interview soon after delivery yielded the primary information on exposure. Of the 783 mothers who reported noise exposure in the first trimester, 370 were case mothers and 413 were referents. Hygienic assessment indicated that 102 case mothers and 103 referents had been exposed in the first trimester to a sound level of around $80 \mathrm{~dB} \mathrm{~L} \mathrm{~L}_{\text {Aeq }(8 \mathrm{~h})}$ or higher, the overall odds ratio being 1.0 (95\% confidence interval $0.7-1.3$ ). Adjustment for potential confounders by logistic regression methods gave similar results. There was no obvious trend suggesting a hazard when different exposure categories were considered.
\end{abstract}

Key terms: birth defects, occupation, work.

Noise is a common environmental pollutant experienced as a stressor by one-third of the active female work force in Finland (1). Although epidemiologic studies on the effects of environmental, including industrial, factors upon reproductive outcomes have rapidly expanded during recent years, little attention has been focused on noise exposure. According to a recent study, occupational noise exerts direct effects on the fetus, and the effects are detectable in childhood as auditory damage (2). Embryo- or fetotoxic effects via maternal stress response also seem plausible because laboratory animals have shown decreased pregnancy maintenance and reduced fetal weight, and occasionally teratogenic effects, when exposed to noise. (See references 3 and 4.)

In the United States one epidemiologic study has reported a high rate of neural tube defects among infants of mothers residing in noisy areas near the Los Angeles airport (5). Near the Atlanta airport, no marked overall connection was found between environmental noise and the occurrence of birth defects, but the examination of rates of several categories of congenital malformations showed a statistically significant excess of spina bifida without hydrocephalus (6). The case-referent study that was undertaken to study the association more thoroughly did not rule out a slight association between neural tube defects and residence in the high-noise area. Several other kinds of untoward reproductive outcome have also been associated with exposure to noise in human populations $(7-14)$.

1 Institute of Occupational Health, Helsinki, Finland.

Reprint requests to: Dr K Kurppa, Department of Epidemiology and Biostatistics, Institute of Occupational Health, Topeliuksenkatu 41 a A, SF-00250 Helsinki, Finland.
In an attempt to screen for teratogenic effects of various exposures in Finland, we have retrospectively quantified the individual noise exposure of 1475 mothers of infants with selected structural birth defects and an equal number of their time- and area-matched referents. The analyses showed no increased teratogenic risk for infants of mothers who either reported exposure to noise in the first trimester or who were considered exposed according to hygienic criteria.

\section{Subjects and methods}

In Finland, population five million, nearly all deliveries take place in hospitals with both obstetric and pediatric wards. Birth defects found during the first year of life or in stillborn infants weighing over $600 \mathrm{~g}$ must be notified to the Register of Congenital Malformations, which is a national surveillance system that has been in operation since 1963 .

Detailed information on prenatal history has been collected for infants with selected structural malformations. Virtually all these defects have been detected at the delivery hospitals. Special studies based on the Register have been nationwide in coverage and have applied a case-referent design. The infant whose birth immediately preceded that of the case infant in the same maternity care district was taken as a referent. Validity points of the approach have been discussed elsewhere (15).

According to the Register routine, the mothers of case infants and their referents are interviewed by midwives at their maternity care center usually at the time of the first postpartum visit. The interviews consist of some 80 items, including information on the family, previous pregnancies, and details of the latest pregnan- 
cy. The completed interview forms and photocopies of antenatal records are returned to the Register. The retrieval rate of the forms has been better than $99 \%$ (15).

The data collection of the present study started in 1976. All consecutively born infants with central nervous system defects were included. The study was gradually extended to infants with orofacial clefts and structural malformations of the skeleton (excluding club foot and dislocation of the hip), heart, and great vessels. (See reference 16.) A trained pathologist checked the notifications and autopsy reports. Infants with known chromosome anomalies were excluded. A total of 1538 consecutive pairs of infants whose mothers had been interviewed according to the Register routine were eligible for our study. Sixty-three mothers $(2.0 \%)$ of the total of 3076 could not be contacted, declined special interviews, or did not show up for the interview. Valid interviews were completed for 1475 case-referent pairs, ie, for $96 \%$ of the pairs of mothers with eligible infants (table 1).

Two trained interviewers collected data on the mothers' exposures during work and leisure time. The interviews took place at the mother's maternity care center, usually about three months after the delivery. Information on exposures was obtained from the mother's workday description, which was recorded as such, and from fixed questions regarding specific exposures.

Of the 2950 mothers, $2385(81 \%)$ had worked during pregnancy, $2073(70 \%)$ regularly and $312(11 \%)$ temporarily.

The interview had fixed questions on noise exposure and use of hearing protectors during pregnancy. A total of $783(27 \%)$ of all the mothers reported noise exposure in the first trimester, ie, $774(32 \%)$ of the mothers who had worked and $9(2 \%)$ of those who had not worked. Of the mothers who had reported noise in the first trimester, 100 had used hearing protectors.

Throughout the study the persons making the exposure categorizations were unaware of the case-referent status of the infants. All of the 2950 interview forms were provisionally assessed at exposure meetings, attended by an industrial hygienist and two experts in occupational health, which convened regularly

Table 1. Composition of the study population that completed the special interviews on occupational and leisure-time exposures.

\begin{tabular}{lcll}
\hline $\begin{array}{l}\text { Malformation } \\
\text { group }\end{array}$ & $\begin{array}{l}\text { Number } \\
\text { of pairs }\end{array}$ & Period of data collection \\
\hline $\begin{array}{l}\text { Central nervous } \\
\text { system defects }\end{array}$ & 365 & June & 1976 - December 1982 \\
$\begin{array}{l}\text { Oral clefts } \\
\text { Skeletal defects }\end{array}$ & 581 & December 1977 - December 1982 \\
Cardiovascular & 360 & December 1979 - December 1982 \\
defects & 169 & January & 1980 - December 1981 \\
\hline Total & 1475 & & \\
\hline
\end{tabular}

during the 6.5 years of data collection. Workday description, the fixed question on noise exposure, hours of exposure per day, use of hearing protectors, and the results of possible noise measurements were noted. The group used the $80 \mathrm{~dB} 8$-h equivalent continuous A-weighted sound level $\left(\mathrm{L}_{\text {Aeq }(8 \mathrm{~h}}\right)$ as the approximate cut-off level for reasonable noise exposure (17). Exposures to several other types of occupational and leisure-time factors were classified at the same time (16).

The aforementioned exposure meetings had considered 220 mothers exposed to noise in the first trimester. In 66 instances $(30 \%)$ information on actual noise measurement at the mother's workplace was available, and in 145 instances $(66 \%)$ information on measurements at closely comparable workplaces could be utilized for exposure categorization by the analogy principle. For nine mothers $(4 \%)$ the assessment was solely based on the hygienist's judgment.

Finally, two hygienists, one a member of the study team and the other an expert on noise measurements, independently perused the interview forms of the 220 exposed mothers. Their forms were mixed with interview forms of an additional 100 mothers who had not been considered noteworthily exposed to noise. These 100 mothers were made up of two random samples, 50 mothers who had reported noise in response to the interview question and 50 who had not. The hygienists were unaware of which form belonged to which of the groups. Preselected exposure categories were the objective, and the selected noise levels were considered to represent ordinal-scaled exposure categories of (i) "no" appreciable exposure (clearly less than $80 \mathrm{~dB}$ $\mathrm{L}_{\mathrm{Aeq}(\mathrm{B})}$ ), (ii) exposure of "low" intensity (around $\left.80 \mathrm{~dB} \mathrm{~L}_{\text {Acq }(\mathrm{B} h)}\right)$, (iii) exposure of "moderate" intensity (around $85 \mathrm{~dB} \mathrm{~L}_{\mathrm{Aeq}(8 \mathrm{~h})}$ ), and (iv) exposure of "high" intensity (around $90 \mathrm{~dB} \mathrm{~L}_{\mathrm{Acq}(8 \mathrm{~h} \text { ) }}$ or higher). These categories were chosen because the hygienists felt reasonably comfortable as to their ability (i) to differentiate most of the "unexposed" mothers from those exposed to noise of around $80 \mathrm{~dB} \mathrm{~L}_{\text {Aeq ( } 8 \mathrm{~h})}$ or above and (ii) to discern exposure to less intense noise from that of more intense noise. Finally, the information on each mother who did not receive the same classification was considered by both hygienists jointly, and the category best agreeable was chosen.

The hygienists' assessments for the 220 mothers who had been provisionally considered exposed are crosstabulated in table 2. The hygienists independently categorized 182 of them as exposed and nine as unexposed. After jointly examining the exposure information of the remaining 29 mothers, the hygienists regarded 26 of them as exposed and three as unexposed. Thus, of the 220 mothers that had been considered exposed in the exposure meetings, $208(94.5 \%)$ were also classed as such in the final scrutiny. Exposure included the first trimester for 205 of the mothers. The remaining 2745 mothers were considered unexposed in the first trimester. 
In the exposure meetings 2730 mothers had been assessed as unexposed. In the sample of 50 mothers of the 2107 who had not reported noise exposure, the hygienists agreed on nonexposure in all instances. Of the sample of 50 mothers who had reported exposure (623 mothers), and yet had been considered unexposed, the hygienists agreed that five should be regarded as exposed. According to these sample findings, some $2 \%$ of the unexposed mothers had been misclassified in the exposure meetings. The error was considered tolerable, and no further effort was made to identify the misclassified mothers individually.

The matching procedure had not correlated the case and reference series with respect to noise exposure, and therefore the data were analyzed unmatched to gain more efficiency. [See references 18 and 19 (p 280).] Confidence intervals for the crude odds ratios were calculated with the modified Cornfield method $(20,21)$. Power calculations for single $2 \times 2$ tables were carried out with methods derived by Miettinen (22) with a significance level of $\alpha=0.025$ and a one-sided test.

In the adjustment, unconditional logistic regression modeling, mathematically identical to follow-up studies, was used (23). The variables that were controlled in the comparisons were mother's employment, exposure to solvents in the first trimester, age, parity, previous miscarriages, induced abortions, stillbirths, previous child with malformation, common cold or fever in the first trimester, intake of analgetics or antipyretics, intake of sedatives or soporifics in the first trimester, alcohol intake, and smoking during pregnancy.

Of the mothers who were employed during pregnancy and had been exposed to noise, $95 \%$ belonged to the category of manual workers according to the socioeconomic classification (24), whereas $27 \%$ of the unexposed mothers were manual workers. All exposed women had been employed in nonagricultural work. Control of possible confounding was done by a separate analysis which was restricted to the category of nonagricultural manual workers.

\section{Results}

Table 3 shows that 402 case mothers and 440 reference mothers had reported noise exposure during pregnancy, 370 of the former and 413 of the latter in the first trimester. The crude odds ratios were below unity or near it for all the malformation groups under study. Many of the reported exposures had occurred in banks, coffee bars, shops, or schools. Street noise and children yelling also often appeared in the interview forms.

According to the hygienists 205 mothers had been exposed to noise of at least low intensity in the first trimester. Table 4 shows the distribution of these mothers by the industries in which the noise exposure had occurred. Of the mothers, $44.4 \%$ had worked in the textile or clothing industry, and the rest in several other economic fields.

When the mothers were grouped according to the hygienists' judgment of exposure, it appeared that 102 case mothers and 103 reference mothers had been exposed to noise of at least low intensity in the first trimester (table 5). The crude odds ratios showed no statistically significant indications of a teratogenic risk in any malformation group.

Table 2. Correspondence of the two industrial hygienists ${ }^{2}$ independent assessments of the noise exposure ${ }^{a}$ of the 220 mothers considered exposed in the exposure meetings. The approved final numbers for the exposure categories are given in parentheses.

\begin{tabular}{lrrrrrr}
\hline $\begin{array}{l}\text { Evaluation of } \\
\text { hygienist } \mathrm{I}^{\mathrm{b}}\end{array}$ & \multicolumn{5}{c}{ Evaluation of hygienist Ic } \\
\cline { 2 - 7 } & Unexposed & Low & Moderate & High & Total \\
\hline Unexposed & 9 & $(12)$ & 4 & - & - & 13 \\
Low & 22 & 82 & $(123)$ & 5 & - & 109 \\
Moderate & 3 & 33 & $22(63)$ & 5 & 63 \\
High & - & 8 & 19 & $8(22)$ & 35 \\
\hline Total & 34 & 127 & 46 & 13 & 220 \\
\hline
\end{tabular}

a Unexposed $=$ clearly less than $80 \mathrm{~dB} L$ low $=$ around $80 \mathrm{~dB}$ $\mathrm{L}_{\mathrm{Aeq}}(8 \mathrm{~h})$, moderate $=$ around $85 \mathrm{~dB} \mathrm{~L}_{\mathrm{Aeq}}(8 \mathrm{~h})$, $\mathrm{high}=$ around $90 \mathrm{~dB}$ $L_{A B q}(8 h)$ or higher $\left(L_{A e q}(8 n)=8\right.$-h equivalent continuous $A$-weighted sound (8) or level).

b Expert on noise measurements.

- Member of the study group.

Table 3. Case and reference mothers according to reported noise exposure in response to the fixed question.

\begin{tabular}{|c|c|c|c|c|c|c|}
\hline \multirow{3}{*}{$\begin{array}{l}\text { Malformation } \\
\text { group }\end{array}$} & \multirow{3}{*}{$\begin{array}{l}\text { Number of } \\
\text { mothers }\end{array}$} & \multirow{3}{*}{$\begin{array}{l}\text { No noise } \\
\text { exposure }\end{array}$} & \multicolumn{4}{|c|}{ Noise exposure reported by mother } \\
\hline & & & \multirow{2}{*}{$\begin{array}{l}\text { Any } \\
\text { trimester } \\
(\mathrm{N})\end{array}$} & \multicolumn{3}{|c|}{ First trimester } \\
\hline & & & & $N$ & $\begin{array}{c}\text { Crude } \\
\text { odds ratioa }\end{array}$ & $\begin{array}{l}95 \% \text { confidence } \\
\text { interval }\end{array}$ \\
\hline \multicolumn{7}{|l|}{ Central nervous } \\
\hline system defects & 365 & 294 & 77 & 71 & 0.6 & $0.5-0.8$ \\
\hline Orofacial clefts & 581 & 430 & 164 & 151 & 0.9 & $0.7-1.1$ \\
\hline Skeletal defects & 360 & 265 & 106 & 95 & 0.9 & $0.7-1.2$ \\
\hline Cardiovascular defects & 169 & 116 & 55 & 53 & 1.2 & $0.8-1.7$ \\
\hline All case mothers pooled & 1475 & 1105 & 402 & 370 & 0.9 & $0.7-1.0$ \\
\hline Referents & 1475 & 1062 & 440 & 413 & & \\
\hline
\end{tabular}

a Contrasted to no reported exposure in the first trimester. 
Table 6 shows the crude and adjusted odds ratio point estimates and their $95 \%$ confidence intervals for an overall teratogenic risk according to exposure intensity. There was no obvious trend suggesting a hazard. For the low and moderate intensity levels the results did not suggest a teratogenic effect for noise exposure. For exposure to a high intensity of noise the adjusted odds ratio was 1.7 , but the lower confidence limit was below unity. In the pooled material, the adjusted odds ratio was 1.0 [95\% confidence interval $(95 \% \mathrm{CI}) 0.8-1.4]$ for exposure to noise of at least low intensity in the first trimester. When the analysis

Table 4. Industries in which mothers (both case and reference) exposed to noise in the first trimester worked.

\begin{tabular}{|c|c|c|c|c|c|}
\hline \multirow{3}{*}{ Industry } & \multicolumn{5}{|c|}{ Noise intensitya } \\
\hline & \multirow{2}{*}{ Low } & \multirow{2}{*}{ Moderate } & \multirow{2}{*}{ High } & \multicolumn{2}{|c|}{ Total exposed } \\
\hline & & & & $\mathrm{N}$ & $\%$ \\
\hline $\begin{array}{l}\text { Textile mills, textile } \\
\text { and clothing }\end{array}$ & 72 & 15 & 4 & 91 & 44.4 \\
\hline Food, dairy & 23 & 9 & 3 & 35 & 17.1 \\
\hline $\begin{array}{l}\text { Sawmill, plywood and } \\
\text { furniture }\end{array}$ & 1 & 19 & 3 & 23 & 11.2 \\
\hline Metal, shipyards & 3 & 8 & 8 & 19 & 9.3 \\
\hline Other & 21 & 12 & 4 & 37 & 18.0 \\
\hline Total & 120 & 63 & 22 & 205 & 100.0 \\
\hline
\end{tabular}

a See table 2 for a definition of the noise intensity. was restricted to the socioeconomic category of manual workers in nonagricultural jobs, the adjusted overall odds ratio was $1.1(95 \% \mathrm{CI} 0.7-1.5)$

Forty-two out of 102 case mothers and 36 out of 103 reference mothers who were considered exposed to noise in the first trimester had worn hearing protectors during pregnancy. Table 7 shows distributions of case and reference mothers according to reported use of hearing protectors without suggesting differences between the groups. The exposed mothers, all combined, who had not used protectors showed an adjusted overall odds ratio of 0.9 (95\% CI $0.6-1.3)$, and those who had used protectors $1.2(95 \% \mathrm{CI}$ $0.7-1.9)$.

\section{Discussion}

Some animal studies have shown that noise exposure may produce reproductive disturbances, including teratogenicity, the suggested mechanisms being the stressinduced increase of catecholamine levels and vasoconstriction in placental vasculature. (See references 3 and 4.) Perception of noise seems more decisive for the induction of human stress than the actual noise intensity is (25). Consequently, we analyzed the data by using both an objective and a subjective noise categorization. The results of neither approach suggested that

Table 5. Case and reference mothers according to the hygienists' assessment of the 8-h equivalent continuous A-weighted

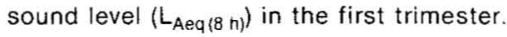

\begin{tabular}{|c|c|c|c|c|c|c|c|c|}
\hline \multirow{3}{*}{$\begin{array}{l}\text { Malformation } \\
\text { group }\end{array}$} & \multirow{3}{*}{$\begin{array}{c}\text { Number } \\
\text { of } \\
\text { mothers }\end{array}$} & \multicolumn{7}{|c|}{ Exposure intensity ${ }^{a}$} \\
\hline & & \multirow[b]{2}{*}{ None } & \multirow[b]{2}{*}{ Low } & \multirow[b]{2}{*}{ Moderate } & \multirow[b]{2}{*}{ High } & \multicolumn{3}{|c|}{ Total exposed } \\
\hline & & & & & & $N$ & $\begin{array}{l}\text { Crude } \\
\text { odds } \\
\text { ratiob }\end{array}$ & $\begin{array}{c}95 \% \\
\text { confidence } \\
\text { interval }\end{array}$ \\
\hline $\begin{array}{l}\text { Central nervous } \\
\text { system defects }\end{array}$ & 365 & 347 & 11 & 5 & 2 & 18 & 0.7 & $0.4-1.2$ \\
\hline Orofacial clefts & 581 & 535 & 27 & 12 & 7 & 46 & 1.1 & $0.8-1.6$ \\
\hline Skeletal defects & 360 & 337 & 14 & 6 & 3 & 23 & 0.9 & $0.6-1.4$ \\
\hline $\begin{array}{l}\text { Cardiovascular } \\
\text { defects }\end{array}$ & 169 & 154 & 9 & 4 & 2 & 15 & 1.3 & $0.7-2.3$ \\
\hline All cases pooled & 1475 & 1373 & 61 & 27 & 14 & 102 & 1.0 & $0.7-1.3$ \\
\hline Referents & 1475 & 1372 & 59 & 36 & 8 & 103 & & \\
\hline
\end{tabular}

a See table 2 for a definition of the exposure intensity.

b Contrasted to the level "no exposure."

Table 6. Odds ratio (OR) point estimates with the $95 \%$ confidence intervals and power calculations by categories of noise exposure in the first trimester, all birth defects pooled.

\begin{tabular}{|c|c|c|c|c|c|c|}
\hline \multirow{2}{*}{$\begin{array}{l}\text { Exposure } \\
\text { intensity }\end{array}$} & \multicolumn{2}{|c|}{ Crude estimates } & \multicolumn{2}{|c|}{ Adjusted estimates } & \multicolumn{2}{|c|}{ Power } \\
\hline & $O R^{b}$ & $\begin{array}{c}95 \% \text { confidence } \\
\text { interval }\end{array}$ & OR & $\begin{array}{c}95 \% \text { confidence } \\
\text { interval }\end{array}$ & $\begin{array}{l}2.5 \text {-fold } \\
\text { risk }\end{array}$ & $\begin{array}{l}2.0 \text {-fold } \\
\text { risk }\end{array}$ \\
\hline Low & 1.0 & $0.7-1.5$ & 1.1 & $0.8-1.6$ & 1.00 & 0.99 \\
\hline Moderate & 0.7 & $0.5-1.2$ & 0.7 & $0.4-1.2$ & 1.00 & 0.95 \\
\hline High & 1.7 & $0.7-4.1$ & 1.7 & $0.7-4.2$ & 0.63 & 0.38 \\
\hline
\end{tabular}

a See table 2 for a definition of the exposure intensity.

b Contrasted to the level "no exposure." 
Table 7. Distributions of case and reference mothers by use of hearing protectors during pregnancy and crude odds ratios.

\begin{tabular}{|c|c|c|c|c|}
\hline $\begin{array}{l}\text { Exposurea in the } \\
\text { first trimester }\end{array}$ & Cases & Referents & $\begin{array}{c}\text { Crude } \\
\text { odds ratio }\end{array}$ & $\begin{array}{c}95 \% \\
\text { confidence } \\
\text { interval }\end{array}$ \\
\hline \multicolumn{5}{|l|}{ Low exposure } \\
\hline $\begin{array}{l}\text { No hearing protectors } \\
\text { Hearing protectors }\end{array}$ & $\begin{array}{l}45 \\
16\end{array}$ & $\begin{array}{r}51 \\
8\end{array}$ & $\begin{array}{l}0.9 \\
2.0\end{array}$ & $\begin{array}{l}0.6-1.3 \\
0.9-4.6\end{array}$ \\
\hline \multicolumn{5}{|l|}{ Moderate exposure } \\
\hline $\begin{array}{l}\text { No hearing protectors } \\
\text { Hearing protectors }\end{array}$ & $\begin{array}{l}13 \\
14\end{array}$ & $\begin{array}{l}15 \\
21\end{array}$ & $\begin{array}{l}0.9 \\
0.7\end{array}$ & $\begin{array}{l}0.4-1.8 \\
0.3-1.3\end{array}$ \\
\hline \multicolumn{5}{|l|}{ High exposure } \\
\hline $\begin{array}{l}\text { No hearing protectors } \\
\text { Hearing protectors }\end{array}$ & $\begin{array}{r}2 \\
12\end{array}$ & $\begin{array}{l}1 \\
7\end{array}$ & $\begin{array}{l}2.0 \\
1.7\end{array}$ & $\begin{array}{l}0.3-15.3 \\
0.7-4.2\end{array}$ \\
\hline
\end{tabular}

a See table 2 for a definition of the exposure intensity.

noise might be a major teratogen at levels commonly detectable in Finland.

It is unlikely that the maternal recall or hygienic estimation of noise exposure in our study was biased. The primary information on several factors at worksites and during leisure-time activities was gathered by trained interviewers who were unaware of any specific hypotheses that might be tested. The hygienists made their exposure classification blind as to the case-referent status, and therefore any bias caused by a systematic misclassification of exposure should have been prevented. In the situation of rare exposure, such as noise as assessed by hygienic standards, even a small deviation from full specificity could bias the estimation. After the hygienic check-ups it is reasonable to suppose that very few mothers were falsely categorized as exposed. Allowing for the estimated misclassification rate of nonexposure, approximately $2 \%$, did not influence the results.

According to the results of a Finnish questionnaire study, 29-35\% of the work force find occupational noise annoying (1). In our study $32 \%$ of the working women reported noise exposure during pregnancy, case and reference mothers equally often. For the great majority of the mothers who had reported noise exposure $(75 \%)$, the level of exposure was assessed to be below the selected cut-off level of around $80 \mathrm{~dB}$ $\mathbf{L}_{\text {Aeq (8 h) }}$.

The portion of mothers considered exposed by the hygienists was $7 \%$ of the total, including mothers who worked regularly and mothers who did not. Some $3 \%$ of the mothers had been more markedly (around $85 \mathrm{~dB} \mathrm{~L}_{\text {Aey (8 h) }}$ or higher) exposed, and only $0.7 \%$ of all the mothers had been heavily exposed (around $\left.90 \mathrm{~dB} \mathrm{~L}_{\mathrm{Aeq}(8 \mathrm{~h})}\right)$. Thus, we could not evaluate malformations in relation to high levels of noise exposure.

Environmental noise is a potential problem because of ubiquitous background exposure. However, our criterion of at least around $80 \mathrm{~dB} \mathrm{~L}_{\mathrm{Aeq}}(8 \mathrm{~h})$ for exposure is much higher than typical environmental exposure. Road traffic is the most important source of noise in urban areas. Yet, merely an estimated $12.5 \%$ of the population in European OECD countries are
Table 8. Power calculations for the detection of a teratogenic risk by noise exposure (around $80 \mathrm{~dB} \mathrm{~L}_{\mathrm{Aeq}}(8 \mathrm{~h}$ ) or higher) in the first trimester of the studied pregnancies. $\left(L_{A e q}(8 h)=8-h\right.$ equivalent continuous A-weighted sound level)

\begin{tabular}{lcc}
\hline \multirow{2}{*}{$\begin{array}{l}\text { Malformation } \\
\text { group }\end{array}$} & \multicolumn{2}{c}{ Power of the study } \\
\cline { 2 - 3 } & $\begin{array}{c}2.0 \text {-fold } \\
\text { risk }\end{array}$ & $\begin{array}{c}1.5 \text {-fold } \\
\text { risk }\end{array}$ \\
\hline $\begin{array}{l}\text { Central nervous } \\
\text { system defects }\end{array}$ & 0.94 & 0.53 \\
$\begin{array}{l}\text { Orofacial clefts } \\
\text { Skeletal defects }\end{array}$ & 0.99 & 0.66 \\
Cardiovascular & 0.94 & 0.53 \\
defects & 0.76 & 0.34 \\
\hline $\begin{array}{l}\text { All birth defects } \\
\text { pooled }\end{array}$ & 1.00 & 0.86 \\
\hline
\end{tabular}

exposed to daytime road traffic noise higher than $65 \mathrm{~dB} \mathrm{~L}_{\text {Aeq }}$, and only $0.3 \%$ to daytime aircraft noise exceeding $65 \mathrm{~dB} \mathrm{~L} \mathrm{~L}_{\text {Aeq }}$ (26). Exposure can vary considerably due to traffic density and type of conurbation, but Finland has a relatively low density of population. When compared to typical noise exposure at industrial workplaces, the contribution due to transport noise in the total noise immission level is small.

As regards the mothers objectively exposed (hygienic estimate), the study had sufficient power to detect a 1.5 -fold overall risk with a $86 \%$ chance (table 8 ). For the studied malformation subgroups, the power of the study was sufficient for a reasonable chance of detecting a 2.0-fold risk. When the scrutiny was limited to the category of high noise exposure, assessed as around $90 \mathrm{~dB} \mathrm{~L}$ Aeq (8 h), the power of the study was poor (table 6).

In summary, the results of the present study did not indicate a teratogenic risk for infants of mothers exposed to noise in the first trimester of pregnancy. Numerical limitations prevent detailed generalizations as in most other epidemiologic studies on teratogenicity. The results do not apply directly to very intense noise exposure nor to narrowly defined malformation categories. Yet, we are inclined to conclude that noise exposure in a society such as Finland's today is not likely to be an important teratogenic risk factor. 


\section{Acknowledgments}

We thank Ms R Paavola and Ms T Suomela for their skillful technical help and the Finnish Work Environment Fund for its financial support.

\section{References}

1. Katilainen R. Työolosuhdetiedustelu 1977. Helsinki: Tilastokeskus - Statistikcentralen, Valtion painatuskeskus, 1978: 37. (Tilastotiedotus - Statistisk rapport). (ISSN 0355-2357)

2. Lalande NM, Hétu R, Lambert J. Is occupational noise exposure during pregnancy a risk factor of damage to the auditory system of the fetus? Am J Ind Med 1986; 10:427-35.

3. Cook RO, Nawrot PS, Hamm CW. Effects of high frequency noise on prenatal development and maternal plasma and uterine catecholamine concentrations in the CD-1 mouse. Toxicol Appl Pharmacol 1982;66:338-48

4. Fanghänel J, Schumacher G-H. Environmental effects on normogenesis and teratogenesis, with special regard to noise and vibration. In: Persaud TVN, ed. Advances in the study of birth defects; vol 2 (Teratological testing). Lancaster (England): MTP Press, 1979:325-52.

5. Jones FN, Tauscher J. Residence under an airport landing pattern as a factor in teratism. Arch Environ Health 1978;33:10-2.

6. Edmonds LD, Layde PM, Erickson LD. Airport noise and teratogenesis. Arch Environ Health 1979;34:243-7.

7. Ando $Y$, Hattori $H$. Statistical studies on the effects of intense noise during human fetal life. J Sound Vib 1973;27:101-10.

8. Ando $\mathrm{Y}$, Hattori $\mathrm{H}$. Effects of noise on human placental lactogen (HPL) levels in maternal plasma. $\mathrm{Br} \mathrm{J} \mathrm{Ob-}$ stet Gynaecol 1977;84:115-8.

9. Heidam LZ. Spontaneous abortions among dental assistants, factory workers, painters, and gardening workers: a follow-up study. J Epidemiol Community Health 1984;38:149-55.

10. Knipschild P, Meijer H, Sallé H. Aircraft noise and birth weight. Int Arch Occup Environ Health 1981; 48:131-6.

11. Mamelle N, Laumon B, Lazar P. Prematurity and occupational activity during pregnancy. Am J Epidemiol 1984;119:309-22.

12. Rachootin $\mathbf{P}$, Olsen $\mathrm{J}$. The risk of infertility and delayed conception associated with exposures in the Danish workplace. J Occup Med 1983;25:394-402.

13. Rehm S, Jansen $G$. Aircraft noise and premature birth J Sound Vib 1978;59:133-5.

14. Schell LM. Environmental noise and human prenatal growth. Am J Phys Anthropol 1981;56:63-70.

15. Saxén L. Twenty years of study of the etiology of congenital malformations in Finland. In: Kalter H, ed. Issues and reviews in teratology; vol 1. New York, New York: Plenum Publishing Corporation, 1983:73-110.

16. Kurppa K, Holmberg PC, Hernberg S, Rantala K, Riala R, Nurminen T. Screening for occupational exposures and congenital malformations: preliminary results from a nationwide case-referent study. Scand J Work Environ Health 1983;9:89-93.

17. International Organization for Standardization (ISO). Acoustics - determination of occupational noise exposure and estimation of noise induced hearing impairment. Geneva: ISO, 1985. (ISO/DIS 1999.2).

18. Miettinen OS. The matched pairs design in the case of all-or-none responses. Biometrics 1968;24:339-52.

19. Rothman KJ. Modern epidemiology. Boston, Massachusetts: Little, Brown and Company, 1986.

20. Cornfield J. A statistical problem arising from retrospective studies. In: Neyman J, ed. Proceedings of third Berkeley symposium on mathematical statistics and probability. Berkeley and Los Angeles, California: University of California Press, 1956:135-48.

21. Miettinen $O$, Nurminen M. Comparative analysis of two rates. Stat Med 1985;4:213-26.

22. Miettinen OS. Individual matching with multiple controls in the case of all or none responses. Biometrics 1969;25:339- 54 .

23. Prentice RL, Pyke R. Logistic disease incidence models and case-control data. Biometrika 1979;66:408-12.

24. Central Statistical Office of Finland. Classification of occupations 1980. Helsinki: Central Statistical Office of Finland, 1981. (Handbook no 14.)

25. van Dijk FJH, Souman AM, de Vries FF. Non-auditory effects of noise in industry: VI. a final field study in industry. Int Arch Occup Environ Health 1987;59: $133-45$.

26. Organization for Economic Co-operation and Development. OECD environmental data compendium 1985. Paris: Organization for Economic Co-operation and Development, 1985. 297 p.

Received for publication: 3 October 1988 